\title{
Histone deacetylase inhibitors induce growth inhibition, cell cycle arrest and apoptosis in human choriocarcinoma cells
}

\author{
NORIYUKI TAKAI, TAMI UEDA, MASAKAZU NISHIDA, KAEI NASU and HISASHI NARAHARA \\ Department of Obstetrics and Gynecology, Oita University Faculty of Medicine, Oita, Japan
}

Received July 13, 2007; Accepted August 21, 2007

\begin{abstract}
We investigated the effect of five histone deacetylase inhibitors (HDACIs) on the choriocarcinoma cell line, BeWo. BeWo cells were treated with various concentrations of five HDACIs, and their effects on cell growth, cell cycle, apoptosis, and related measurements were investigated. 3-(4,5-dimethylthiazol-2-yl)-2,5-diphenyltetrazolium bromide assays showed that the BeWo choriocarcinoma cell line was sensitive to the growth inhibitory effect of five HDACIs. Cell cycle analysis indicated that exposure to HDACIs decreased the proportion of cells in the $\mathrm{S}$-phase and increased the proportion in the G0/G1 phases of the cell cycle. Induction of apoptosis was confirmed by annexin $\mathrm{V}$ staining of externalized phosphatidylserine and loss of the transmembrane potential of mitochondria. This induction occurred in concert with altered expression of genes related to cell growth, malignant phenotype, and apoptosis. Furthermore, HDACI treatment of this cell line increased acetylation of $\mathrm{H} 3$ and $\mathrm{H} 4$ histone tails. These results raise the possibility that HDACIs may prove particularly effective in the treatment of choriocarcinoma.
\end{abstract}

\section{Introduction}

Gestational choriocarcinomas, a group of rare placenta disorders, have a varying potential for invasion, either local, or remote under the form of metastases. Women with gestational choriocarcinoma who fail to respond to wellestablished first-line chemotherapy have an extremely poor prognosis in spite of multiagent chemotherapy (1-3). Definitive second-line and third-line chemotherapy regimens remain to be identified, and newer cytotoxic agents are of interest in this regard.

One of the most important mechanisms in chromatin remodeling is the post-translational modification of the $\mathrm{N}$ -

Correspondence to: Dr Noriyuki Takai, Department of Obstetrics and Gynecology, Oita University Faculty of Medicine, 1-1 Idaigaoka, Hasama-machi, Yufu-shi, Oita 879-5593, Japan E-mail: takai@med.oita-u.ac.jp

Key words: cell cycle, apoptosis, acetylation, choriocarcinoma terminal tails of histones by acetylation, which contributes to a 'histone code' determining the activity of target genes (4). Transcriptionally silent chromatin is composed of nucleosomes in which the histones have low levels of acetylation on the lysine residues of their amino-terminal tails. Acetylation of histone proteins neutralizes the positive charge on lysine residues and disrupts nucleosome structure, allowing unfolding of the associated DNA with subsequent access by transcription factors, resulting in changes in gene expression.

Acetylation of core nucleosomal histones is regulated by the opposing activities of histone acetyltransferases (HATs) and histone deacetylases (HDACs). HDACs catalyze the removal of acetyl groups on the amino-terminal lysine residues of core nucleosomal histones, and this activity is generally associated with transcriptional repression. Aberrant recruitment of HDAC activity has been associated with the development of certain human cancers (5). Transcription factors such as Mad-1, BCL-6, and ETO have also been shown to assemble HDAC-dependent transcriptional repressor complexes (6-8).

HDAC inhibitors (HDACIs) such as trichostatin A (TSA) and sodium butyrate $(\mathrm{NaB})$ can inhibit cancer cell growth in vitro (9) and in vivo (10), revert oncogene-transformed cell morphology (11), induce apoptosis (12), and enhance cell differentiation (13). Several classes of HDACIs have been identified, including: a) short-chain fatty acids [e.g., butyrates and valproic acid (VPA)]; b) organic hydroxamic acids [e.g., TSA and suberoyl anilide bishydroxamine (SAHA)]; c) cyclic tetrapeptides (e.g., trapoxin); and d) benzamides (e.g., MS-275) (14). The structure of SAHA is related to that of TSA, a natural product isolated from Streptomyces hygroscopicus that was initially used as an antifungal antibiotic (14). Phenylbutyrate has been used as a single agent in the treatment of $\beta$-thalassemia, toxoplasmosis, and malaria.

Some HDACIs (e.g., TSA and trapoxin) are of limited therapeutic use due to poor bioavailability in vivo as well as toxic side effects at high doses. $\mathrm{NaB}$ and phenylbutyrate are degraded rapidly after intravenous administration and therefore require high doses exceeding $400 \mathrm{mg} / \mathrm{kg} / \mathrm{day}$ (15). Furthermore, these compounds are not specific for HDACs, as they also inhibit phosphorylation and methylation of proteins as well as DNA methylation (16).

VPA, however, is relatively safe and non-toxic in vivo; and for this reason, we focused on VPA in this study. VPA is an established drug, used for almost 30 years in the long-term therapy of epilepsy. CBHA, m-carboxycinnamic acid 
bishydroxamide, is a member of a recently synthesized family of hybrid polar compounds that have been shown to be inhibitors of HDAC (17) and potent inducers of transformed cell growth arrest and terminal differentiation at micromolar $\left(\mathrm{LD}_{50}\right.$ range, 1-4 $\left.\mu \mathrm{M}\right)$ concentrations (18). Synthetic amide analogs were discovered to have a common structure with TSA (19). Using an in vitro enzyme inhibition assay of histone deacetylation, Jung et al demonstrated that M344 is a potent HDACI and an inducer of terminal cell differentiation (19). MS-275 (MS-27-275; 3-pyridylmethyl$\mathrm{N}$-\{4-[(2-aminophenyl)-carbamoyl]-benzyl-carbamate $\}$ is a highly potent histone deacetylase inhibitor that also induces the expression of the cyclin-dependent kinase inhibitor p21 WAF1/CIP1 and gelsolin, and changes the cell cycle distribution $(20,21)$. MS-275 has shown antiproliferative activity in various in vitro and in vivo human tumor models $(20,22)$, and is currently being tested in clinical trials involving patients with solid tumors or hematological malignancies (23). Synthetic analogs isolated from screening libraries (Oxamflatin, Scriptaid) were discovered to have a common structure with TSA and SAHA, that is, an hydroxamic acid zinc-binding group linked via a spacer $(5$ or $6 \mathrm{CH} 2)$ to a hydrophobic group (24). Using an immunoblotting assay of histone deacetylation, $\mathrm{Su}$ et al demonstrated that Scriptaid is a potent HDACI with a $>100$-fold increase in histone acetylation with relatively low toxicity (24).

However, little information is available concerning the effects of HDACIs on choriocarcinomal cells. This study was designed to define the biologic and therapeutic effects of five HDACIs in treating choriocarcinoma. We examined whether these compounds were able to mediate inhibition of cell growth, cell cycle arrest, apoptosis, and expression of genes related to the malignant phenotype in the choriocarcinoma cell line.

\section{Materials and methods}

Cell line. The BeWo human choriocarcinoma cell line was obtained from the Riken (Ibaraki, Japan). The BeWo cells were maintained as monolayers at $37^{\circ} \mathrm{C}$ in $5 \% \mathrm{CO}_{2} /$ air in HamF12 (Gibco, Rockville, MD) containing 10\% heatinactivated fetal bovine serum (FBS) (Omega, Tarzana, CA).

Chemicals. VPA was obtained from Sigma (St. Louis, MO). VPA was dissolved in phosphate-buffered saline (PBS) to a 1-M stock solution. CBHA was obtained from Calbiochem (San Diego, CA). CBHA was dissolved in anhydrous dimethyl sulfoxide (DMSO) to a 100-mM stock solution. Subsequent dilutions were made in $1 \mathrm{mM}$ fatty acid-free bovine serum albumin (BSA). M344, the 4-dimethylamino-N-(6-hydroxycarbamoyl-hexyl)-benzamide, was obtained from BioVision (Mountain View, CA). M344 was dissolved in anhydrous DMSO to a $100-\mathrm{mM}$ stock solution. Subsequent dilutions were made in $1 \mathrm{mM}$ fatty acid-free BSA. MS-275 was obtained from Calbiochem. MS-275 was dissolved in anhydrous DMSO to a $100-\mathrm{mM}$ stock solution. Subsequent dilutions were made in $1 \mathrm{mM}$ fatty acid-free BSA. Scriptaid, the 6-(1,3-dioxo-1H,3H-benzo[de] isoquinolin-2-yl)hexanoic acid hydroxyamide, was obtained from Biomol (Plymouth Meeting, PA). Scriptaid was dissolved in anhydrous
DMSO to a $100-\mathrm{mM}$ stock solution. Subsequent dilutions were made in $1 \mathrm{mM}$ fatty acid-free BSA.

MTT assays. 3-(4,5-dimethylthiazol-2-yl)-2,5-diphenyltetrazolium bromide (MTT; Sigma, St. Louis, MO) was placed in solution with PBS $(5 \mathrm{mg} / \mathrm{ml})$ and was used to measure cellular proliferation. Cells $\left(1 \times 10^{3}\right)$ were incubated in $100 \mu \mathrm{l}$ of culture medium for $48 \mathrm{~h}$ in $96-$ well plates, and $10 \mu 1$ of MTT solution was added. After $4 \mathrm{~h}$ of incubation, $50 \mu 1$ of solubilization solution (20\% SDS) was added, and cells were then incubated at $37^{\circ} \mathrm{C}$ for $16 \mathrm{~h}$. In this assay, MTT was cleaved to an orange formazan dye by metabolically active cells. The dye was directly quantified using an enzymelinked immunoabsorbent assay reader at $540 \mathrm{~nm}$.

All experiments were conducted independently at least three times in triplicate per experimental point.

Cell cycle analysis by flow cytometry. The cell cycle was analyzed by flow cytometry after 2 days of culturing either with or without HDACIs, as described $(25,26)$. BeWo cells $\left(5 \times 10^{4}\right)$ were exposed to HDACIs in 6-well, flat-bottomed plates for $48 \mathrm{~h}$. Total cells, both in the suspension and adherent, were collected, washed, and suspended in cold PBS. Cells were fixed in chilled $75 \%$ methanol and stained with propidium iodine (PI). Analysis was performed immediately after staining using the CELLFit program (Becton Dickinson, San Jose, CA), whereby the S-phase was calculated using an RFit model.

All experiments were conducted independently at least three times in triplicate per experimental point.

Measurement of apoptosis (flow cytometry analysis with the annexin V/propidium iodide assay). An early step in the process of cell death (apoptosis and necrosis) is the redistribution of phosphatidylserine (PS) from the inner leaflet to the outer leaflet of the plasma membrane due to the loss of membrane asymmetry (27). The externalized PS can be readily visualized by incubating intact cells with a fluorescent derivative of the protein annexin V, a phospholipid-binding protein. Propidium iodine (PI), a fluorochrome, is used to label DNA. Unlike necrotic cells, apoptotic cells do not lose their cell membrane integrity and are thus impermeable for dyes such as PI. Therefore, the combination of annexin-V and PI staining permits the simultaneous quantification of vital, apoptotic, and necrotic cells .

Cells were plated and grown overnight until they reached $80 \%$ confluence, and then treated with HDACIs. After $48 \mathrm{~h}$, detached cells in the medium were collected, and the remaining adherent cells were harvested by trypsinization. The cells $\left(1 \times 10^{5}\right)$ were washed with PBS and re-suspended in $250 \mu 1$ of binding buffer (annexin V-FITC kit; Becton Dickinson) containing $10 \mu \mathrm{l}$ of $20 \mu \mathrm{g} / \mathrm{ml}$ PI and $5 \mu \mathrm{l}$ of annexin V-FITC, which binds to phosphatidylserine translocated to the exterior of the cell membrane early in the apoptosis pathway as well as during necrosis. After incubation for $10 \mathrm{~min}$ at room temperature in a light-protected area, the samples were analyzed on a FACSCalibur flow cytometer (Becton Dickinson). FITC and PI emissions were detected in the FL-1 and FL-2 channels, respectively. For each sample, data from 30,000 cells were recorded in list mode on 
logarithmic scales. Subsequent analysis was done with CellQuest software (Becton Dickinson). We were able to discriminate intact cells (annexin $/ \mathrm{PI}^{-}$) from apoptotic cells $\left(\right.$ annexin $\left.{ }^{+} / \mathrm{PI}^{-}\right)$and necrotic cells $\left(\right.$annexin $\left.{ }^{+} / \mathrm{PI}^{+}\right)$after treatment with HDACIs.

All experiments were conducted independently at least three times in triplicate per experimental point.

Mitochondrial transmembrane potential. The electron gradient across the mitochondrial membrane space during normal respiration is called the mitochondrial transmembrane potential (MTP). Disruption of the MTP is one of the earliest intracellular events following the induction of apoptosis. The MitoCapture Apoptosis Detection kit (Biovision Research Products, Palo Alto, CA) provides a simple, fluorescentbased method for distinguishing between healthy and apoptotic cells by detecting the changes in MTP. The kit utilizes MitoCapture, a cationic dye that fluoresces differently in healthy and apoptotic cells. In healthy cells, MitoCapture accumulates and aggregates in the mitochondria, giving off a bright red fluorescence. In apoptotic cells, MitoCapture cannot aggregate in the mitochondria due to the altered mitochondrial transmembrane potential, and it therefore remains in the cytoplasm in its monomer form, fluorescing green. The fluorescent signals can be easily detected by fluorescence microscopy using a band-pass filter (detects FITC and rhodamine) or analyzed by flow cytometry using the FITC channel for green monomers $(525 \mathrm{~nm})$ and the PI channel for red aggregates $(575 \mathrm{~nm})$.

Cells were prepared for FACS as described above and stained using the MitoCapture Apoptosis Detection kit with a fluorescent lipophilic cationic reagent that assesses mitochondrial membrane permeability, according to the manufacturer's recommendations. Briefly, cells were incubated with the MitoCapture reagent at $37^{\circ} \mathrm{C}$ in a $5 \% \mathrm{CO}_{2}$ incubator for $15 \mathrm{~min}$. This assay uses an intramitochondrial dye, which forms aggregates in healthy cells, leading to increased 575 fluorescence (PI channel, FL-2) and indicating a normal MTP. In apoptotic cells, however, the dye is excluded from the mitochondria, leading to a loss of 575 fluorescence (aggregate) and an increase in 525 fluorescence (FITC channel, FL-1) (monomer). Data were converted to density plots using System 2 software. In some experiments, FACS data were confirmed by fluorescent microscopy using a wide band-pass filter. Cells with intact mitochondria exhibited focal red cytosolic fluorescence, whereas cells with permeabilized mitochondria exhibited diffuse green cytosolic fluorescence. Cells lacking red fluorescence and having green fluorescence were scored positive.

All experiments were conducted independently at least three times in triplicate per experimental point.

Western blot analysis. Cells were washed twice in PBS, suspended in lysis buffer [50 mM Tris ( $\mathrm{pH} 8.0), 150 \mathrm{mM}$ $\mathrm{NaCl}, 0.1 \%$ SDS, $0.5 \%$ sodium deoxycholate, $1 \%$ NP40, phenylmethylsulfonyl fluoride at $100 \mu \mathrm{g} / \mathrm{ml}$, aprotinin at $2 \mu \mathrm{g} / \mathrm{ml}$, pepstatin at $1 \mu \mathrm{g} / \mathrm{ml}$, and leupeptin at $10 \mu \mathrm{g} / \mathrm{ml}$, and placed on ice for $30 \mathrm{~min}$. After centrifugation at $15,000 \mathrm{x} \mathrm{g}$ for $15 \mathrm{~min}$ at $4^{\circ} \mathrm{C}$, the suspension was collected. Protein concentrations were quantified using the Bio-Rad protein
Assay Dye Reagent Concentrate (Bio-Rad Laboratories, Hercules, CA) according to the manufacturer's recommendation. Whole cell lysates $(40 \mu \mathrm{g})$ were resolved by SDS-PAGE in a 4-15\% gel, transferred to a polyvinylidene difuride membrane (Immobilon; Amersham Corp., Arlington Heights, IL), and probed sequentially with antibodies against acetylated H3 (1:1,000, Upstate, Lake Placid, NY), acetylated H4 (1:1,000, Upstate), p21 WAF1 (Ab-1, 1:1,000, Oncogene, San Diego, CA), p27 KIP1 (C-19, 1:1,000, Santa Cruz, CA), cyclin A (clone 25, 1:1,000, BD Pharmingen, San Jose, CA), E-cadherin (G-10, 1:1,000, Santa Cruz, CA), bcl-2 (100, 1:1,000, Santa Cruz, CA), and anti-GAPDH mAb (Research Diagnostics, Flanders, NJ). The blots were developed using the enhanced chemiluminescence (ECL) kit (Amersham).

Statistical analysis. All numerical data were expressed as the average of the values obtained \pm SD. Significance was determined by conducting a paired Student's t-test.

\section{Results}

Effects of HDACIs on the proliferation and viability of the BeWo choriocarcinoma cell line in vitro. We examined the antitumor effects of HDACIs on the BeWo choriocarcinoma cell line in vitro, using an MTT assay with an exposure of 2 days to the HDACIs (Fig. 1). BeWo choriocarcinoma cells showed significant sensitivity to VPA with $1.2 \times 10^{-3} \mathrm{M}$, CBHA with $2.0 \times 10^{-6} \mathrm{M}$, M344 with $7.8 \times 10^{-6} \mathrm{M}, \mathrm{MS}-275$ with $6.3 \times 10^{-6} \mathrm{M}$, and Scriptaid with $2.2 \times 10^{-6} \mathrm{M}$, respectively, which caused a $50 \%$ inhibition $\left(\mathrm{ED}_{50}\right)$ of their growth.

Cell cycle analysis of BeWo choriocarcinoma cells after exposure to HDACIs. BeWo choriocarcinoma cells cultured for 2 days in the presence of five HDACIs showed an accumulation in the $\mathrm{G} 0 / \mathrm{G} 1$ phases of the cell cycle, with a concomitant decrease in the proportion of those in the $S$ phase (Fig. 2). For example, a total of $47.5 \pm 5.7 \%$ of the untreated BeWo cells, compared with $77.1 \pm 10.2 \%$ of cells cultured with $1 \times 10^{-3} \mathrm{M}$ of VPA, was in the G0/G1 phases. A total of $32.9 \pm 4.5 \%$ of the BeWo untreated cells, compared with $8.2 \pm 4.3 \%$ of cells cultured with $1 \times 10^{-3} \mathrm{M}$ of VPA was in the $\mathrm{S}$ phase (Fig. 2). This was representative of all the HDACIs tested.

Apoptotic changes in HDACI-treated BeWo choriocarcinoma cells. To assess the capability of choriocarcinoma cells to undergo apoptosis in response to drug exposure and to help distinguish between different types of cell death, we doublestained HDACI-treated cells with annexin V and PI and analyzed the results using flow cytometry. Annexin V binding combined with PI labeling was performed for the distinction of early apoptotic (annexin $\mathrm{V}^{+}$/propidium iodide-) and necrotic (annexin $\mathrm{V}^{+} /$propidium iodide ${ }^{+}$) cells. At increasing doses of HDACIs, we also detected a simultaneous increase in both the annexin $\mathrm{V}^{+}$/propidium iodide- fraction (early apoptotic) and annexin $\mathrm{V}^{+} /$propidium iodide ${ }^{+}$(regarded as necrotic) subpopulations (Fig. 3A). After incubations with death stimuli ( $1 \times 10^{-3} \mathrm{M}$ of VPA) for $48 \mathrm{~h}, 25 \pm 3 \%$ of BeWo cells were annexin $\mathrm{V}^{+}$/propidium iodide - . However, a similar pattern of labeling was detectable in $\sim 2 \%$ of BeWo cells 

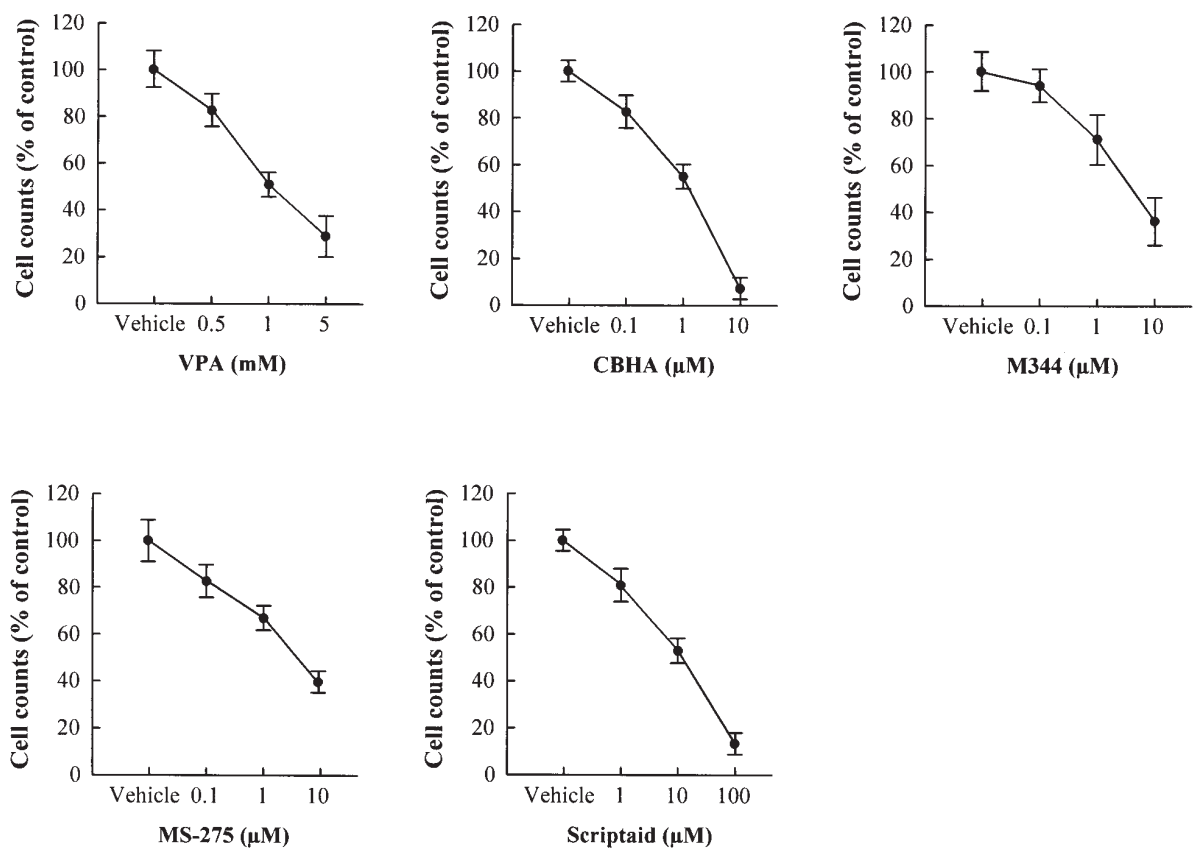

Figure 1. Effect of HDACIs on the growth of the BeWo choriocarcinoma cell line in vitro. BeWo choriocarcinoma cells were treated with either HDACIs at various concentrations or the dilutant (control) for $48 \mathrm{~h}$, and growth (\% of control) was measured by 3-(4,5-dimethylthiazol-2-yl)-2,5-diphenyltetrazolium bromide assay. Results represent the mean \pm SD of three independent experiments with triplicate dishes.

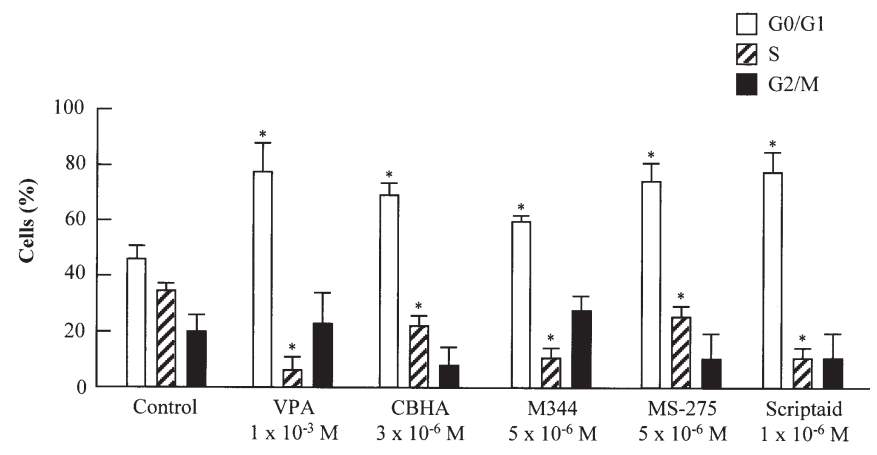

Figure 2. Cell cycle analysis of BeWo cells by flow cytometry. BeWo cells were cultured with HDACIs for $48 \mathrm{~h}$, harvested, and stained with propidium iodine (PI). Control cells were treated with vehicle alone. Cell cycle analysis was performed by flow cytometry (Materials and methods). Results represent the mean $\pm \mathrm{SD}$ of three independent experiments. ${ }^{*} \mathrm{p}<0.05$ as determined by the Student's t-test, difference of experimental compared with the control group.

incubated under normal conditions. The percentage of annexin $\mathrm{V}^{+}$/propidium iodide ${ }^{+}$BeWo cells was $34 \pm 4 \%$ in cultures exposed to noxious stimuli $\left(1 \times 10^{-3} \mathrm{M}\right.$ of VPA) for $48 \mathrm{~h}$, but $12 \%$ in BeWo cells incubated under the normal condition. A typical cyto-diagram obtained by flow cytometry and CellQuest software is shown in Fig. 3A, and the results (mean \pm SD in triplicate) of all of the HDACIs are shown in Table I.

Loss of mitochondrial membrane potential in response to HDACIs. Loss of MTP has been shown to occur prior to nuclear condensation and caspase activation and is linked to cytochrome $c$ release in many, but not all, apoptotic cells $(28,29)$. Using MitoCapture staining and flow cytometry, we
Table I. Cell death measured by annexin V and PI staining detected by flow cytometry in BeWo choriocarcinoma cells.

\begin{tabular}{lccc}
\hline & $\begin{array}{c}\text { Viable } \\
(\mathrm{LL})(\%)\end{array}$ & $\begin{array}{c}\text { Apoptosis } \\
(\mathrm{LR})(\%)\end{array}$ & $\begin{array}{c}\text { Necrosis } \\
(\mathrm{UR})(\%)\end{array}$ \\
\hline Vehicle & $86 \pm 5$ & $2 \pm 1$ & $12 \pm 2$ \\
VPA $\left(1 \times 10^{-3} \mathrm{M}\right)$ & $31 \pm 3$ & $25 \pm 2$ & $34 \pm 5$ \\
CBHA $\left(3 \times 10^{-6} \mathrm{M}\right)$ & $35 \pm 6$ & $30 \pm 6$ & $35 \pm 7$ \\
M344 $\left(5 \times 10^{-6} \mathrm{M}\right)$ & $37 \pm 4$ & $27 \pm 4$ & $36 \pm 10$ \\
MS-275 $\left(5 \times 10^{-6} \mathrm{M}\right)$ & $40 \pm 11$ & $25 \pm 3$ & $35 \pm 13$ \\
Scriptaid $\left(1 \times 10^{-6} \mathrm{M}\right)$ & $32 \pm 8$ & $33 \pm 7$ & $35 \pm 6$ \\
\hline
\end{tabular}

The viable cells were negative for both annexin V and PI staining (the lower left quadrant of the cytograms, LL), apoptotic cells were positive for annexin V staining while negative for PI staining (the lower right quadrant, LR), and necrotic cells were positive for both annexin $V$ and PI staining (the upper right quadrant, UR). Each experiment was repeated three times. Data represent the mean $\pm \mathrm{SD}$.

analyzed the MTP in the HDACI-treated BeWo choriocarcinoma cell line. Intracellular fluorescence was assayed by FACS after loading cells with an intramitochondrial dye. High fluorescence at $575 \mathrm{~nm}$ (FL-2) corresponds to the aggregated form of the dye and is proportional to an intact MTP, whereas loss of MTP leads to a loss of 575 fluorescence and an increase in fluorescence at $525 \mathrm{~nm}$ (FL-1) (monomeric form of the dye). As seen in Fig. 3B, untreated cells exhibited high 575 fluorescence, indicating normal MTP. Treatment of cells with VPA resulted in a loss of 575 fluorescence and an increase in fluorescence at 525, indicating a loss of MTP (Fig. 3B, Table II). 
A

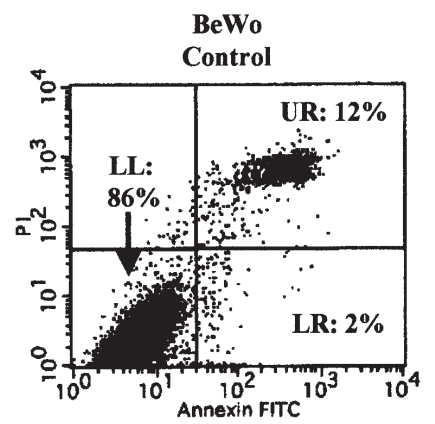

B

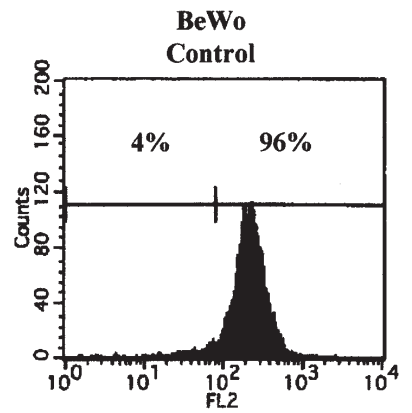

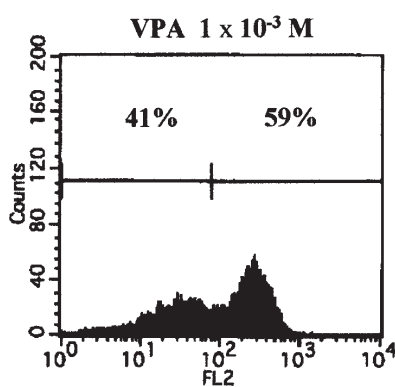

Figure 3. Cell death measured by annexin-V and PI staining, and mitochondrial transmembrane potential detected by flow cytometry. (A) BeWo cells were treated with $1 \times 10^{-3} \mathrm{M}$ of VPA for $48 \mathrm{~h}$. Cells were then stained with annexin V and PI. The positive cells were detected by flow cytometry. The viable cells were negative for both annexin V and PI staining (the lower left quadrant of the cytograms, LL), apoptotic cells were positive for annexin V staining while negative for PI staining (the lower right quadrant, LR), and necrotic cells were positive for both annexin V and PI staining (the upper right quadrant, UR). Each experiment was repeated three times. Two typical flow cytometry results are shown. The left figure shows histograms for untreated cells and the right figure shows those for treated cells at $48 \mathrm{~h}$. (B) The mitochondrial transmembrane potential (MTP) was analyzed using the MitoCapture assay, as described in Materials and methods. BeWo cells were treated with VPA for $48 \mathrm{~h}$ and harvested for flow cytometry. Each histogram profiles the number of cells relative to their fluorescent intensity. In healthy cells, intramitochondrial dye forms aggregates, leading to increased FL-2 fluorescence. In apoptotic cells, the dye is excluded from the mitochondria, leading to a loss of FL-2 fluorescence.

A

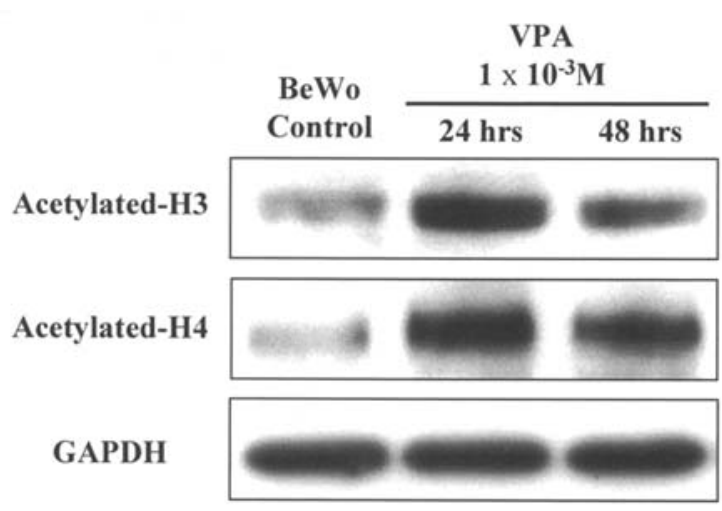

B

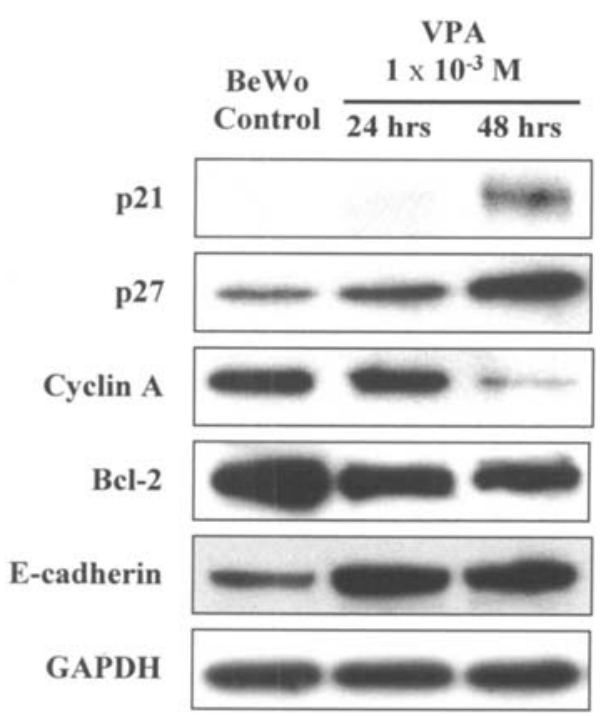

Figure 4. Cell cycle- and apoptosis-related protein expression in BeWo cells, as measured by Western blot analysis. BeWo cells were treated with $1 \times 10^{-3} \mathrm{M}$ VPA, and cell lysates were harvested after 24 and $48 \mathrm{~h}$. Western blot analysis was performed with a series of antibodies: (A) acetylated histone $\mathrm{H} 3$, acetylated histone $\mathrm{H} 4$; (B) $\mathrm{p} 21^{\mathrm{WAF} 1}$, p2 $7^{\mathrm{KIP} 1}$, cyclin A, bcl-2, and E-cadherin. Control cells were treated with vehicle alone. The amount of protein was normalized by comparison to levels of GAPDH.
Table II. Apoptotic cells measured by mitochondrial transmembrane potential in BeWo choriocarcinoma cells.

\begin{tabular}{lcc}
\hline & Viable $(\%)$ & Apoptosis $(\%)$ \\
\hline Vehicle & $96 \pm 4$ & $4 \pm 3$ \\
VPA $\left(1 \times 10^{-3} \mathrm{M}\right)$ & $59 \pm 11$ & $41 \pm 9$ \\
CBHA $\left(3 \times 10^{-6} \mathrm{M}\right)$ & $46 \pm 3$ & $54 \pm 9$ \\
M344 $\left(5 \times 10^{-6} \mathrm{M}\right)$ & $64 \pm 13$ & $36 \pm 8$ \\
MS-275 $\left(5 \times 10^{-6} \mathrm{M}\right)$ & $59 \pm 7$ & $41 \pm 13$ \\
Scriptaid $\left(1 \times 10^{-6} \mathrm{M}\right)$ & $41 \pm 13$ & $59 \pm 16$ \\
\hline
\end{tabular}

Effect of HDACIs on the acetylation of histones. Treatment of the BeWo choriocarcinoma cell line with HDACIs dramatically increased the levels of acetylated $\mathrm{H} 3$ and $\mathrm{H} 4$ (VPA, Fig. 4A; CBHA, M344, MS-275, and Scriptaid, data not shown).

Effect of HDACIs on the expression of cell cycle-and apoptosis-related proteins as well as E-cadherin. $\mathrm{p} 21^{\mathrm{WAF} 1}$ and p27 ${ }^{\mathrm{KIPl}}$ are cyclin-dependent kinase inhibitors (CDKIs) that bind to cyclin-dependent kinase complexes and decrease kinase activity, and they may act as key regulators of the G0/G1 accumulation (reviewed in refs. 25,26). We examined the effect of HDACIs on the expression of $\mathrm{p} 21^{\mathrm{WAF} 1}$ and p27 ${ }^{\mathrm{KIP} 1}$ in the BeWo choriocarcinoma cell line by Western blot analysis (VPA, Fig. 4B; CBHA, M344, MS-275, and Scriptaid, data not shown). HDACIs markedly upregulated the level of $\mathrm{p} 21^{\mathrm{WAF} 1}$ and $\mathrm{p} 27^{\mathrm{KIP1} 1}$ proteins, which were expressed at negligible levels in the untreated BeWo choriocarcinoma cell line. Conversely, HDACIs decreased the levels of cyclin A and decreased bcl-2 levels in the BeWo cells (Fig. 4B). These were representative of all the HDACIs tested.

E-cadherin binds to $B$-catenin and acts as a tumor suppressor gene; its promoter has $\mathrm{CpG}$ islands that are 
frequently methylated in selected cancers. HDACIs markedly increased the expression level of E-cadherin in the BeWo choriocarcinoma cell line.

\section{Discussion}

Epigenetic mechanisms, such as DNA methylation and histone deacetylation, may play a role in the proliferation of human cancer cells. HDACIs can prevent proliferation and induce differentiation of numerous transformed cell types, including neuroblastomas, erythroleukemia, acute myelogenous leukemia, and carcinomas of the skin, breast, prostate, bladder, lung, colon, cervix, endometrium, and ovary (reviewed in refs. 25,26). The effect of HDACIs in human choriocarcinomas, however, has never been fully examined. On the other hand, Rahnama et al reported about epigenetic regulation of human trophoblastic cell migration and invasion (30). They treated BeWo cells with a DNA methyltransferase inhibitor, 5'-aza-2'-deoxycytidine, resulting in conversion of BeWo cells to the non-migratory and noninvasive phenotype. This motivated us to examine the effect of five HDACIs on the BeWo human choriocarcinoma cell line for the first time.

We demonstrated that all of the HDACIs are highly effective in suppressing the growth of human choriocarcinoma cells. These events are associated with the accumulation of acetylated $\mathrm{H} 3$ and $\mathrm{H} 4$ histone proteins. The prominent arrest of cancer cells in the G0/G1 phases of the cell cycle is likely to account for this effect. p2 $1^{\mathrm{WAF} 1}$ and p $27^{\mathrm{KIP} 1}$ are cyclin-dependent kinase inhibitors that have important roles in blocking the cell cycle in the G1 phase $(31,32)$. Protein levels of both $\mathrm{p} 21^{\mathrm{WAF} 1}$ and $\mathrm{p} 27^{\mathrm{KIP} 1}$ increased following treatment of choriocarcinoma cells with HDACIs, supporting their contribution as a possible mechanism by which these agents inhibit choriocarcinoma cell growth.

Our results showed that HDACIs cause decreased expression of cyclin A and increased expression of $\mathrm{p} 21^{\mathrm{WAF} 1}$, which probably combine to modulate the activity of the downstream $\mathrm{pRb} / \mathrm{E} 2 \mathrm{~F}$ axis, triggering cell cycle arrest (33). We showed that treatment with HDACIs dramatically and significantly increased the number of apoptotic cells in the choriocarcinoma cell line. This effect was associated with a decrease in levels of the anti-apoptotic protein bcl-2. The Ecadherin gene is involved in cell-cell adhesion, and loss of function has been associated with enhanced metastatic growth of tumor cells (34). Inactivation of this gene by hypermethylation has been observed in breast carcinoma cells and in primary breast tumors (35). We found that expression of E-cadherin was upregulated in choriocarcinoma cells treated with HDACIs, suggesting a gain of tumor suppressor function in response to inhibition of histone deacetylase.

In summary, this is the first study to report that HDACIs exhibit antiproliferative activity and potently induce apoptosis in human choriocarcinoma cells. These events are accompanied by induction of $\mathrm{p} 21^{\mathrm{WAF} 1}$ and $\mathrm{p} 27^{\mathrm{KIP} 1}$ and down-regulation of several anti-apoptosis- and cell cycle-related proteins, bcl-2, cyclin A, and E-cadherin. The present findings raise the possibility that HDACIs may prove particularly effective in the treatment of choriocarcinomas.

\section{Acknowledgements}

The study was supported by a Grant-in-Aid (no. 16790961 to Noriyuki Takai) for Scientific Research from the Ministry of Education, Culture, Sports, Science, and Technology, Japan.

\section{References}

1. Jones WB, Cardinale C and Lewis JL Jr: Management of the high-risk gestational trophoblastic disease: the Memorial Hospital experience. Int J Gynecol Cancer 7: 27-33, 1997.

2. Berkowitz RS, Goldstein DP and Bernstein MR: Modified triple chemotherapy in the management of high-risk gestational trophoblastic tumors. Gynecol Oncol 19: 173-181, 1984.

3. Surwit EA and Hammond CB: Treatment of metastatic trophoblastic disease with poor prognosis. Obstet Gynecol 55: $565-570,1980$.

4. Strahl BD and Allis CD: The language of covalent histone modifications. Nature 403: 41-45, 2000.

5. Verdin E, Dequiedt F and Kasler HG: Class II histone deacetylases: versatile regulators. Trends Genet 19: 286-293, 2003.

6. Laherty CD, Yang WM, Sun JM, Davie JR, Seto E and Eisenman RN: Histone deacetylases associated with the $\mathrm{mSin} 3$ corepressor mediate mad transcriptional repression. Cell 89: 349-356, 1997.

7. Dhordain P, Lin RJ, Quief S, Lantoine D, Kerckaert JP, Evans RM and Albagli O: The LAZ3(BCL-6) oncoprotein recruits a SMRT/mSIN3A/histone deacetylase containing complex to mediate transcriptional repression. Nucleic Acids Res 26: 4645-4651, 1998.

8. Gelmetti V, Zhang J, Fanelli M, Minucci S, Pelicci PG and Lazar MA: Aberrant recruitment of the nuclear receptor corepressor-histone deacetylase complex by the acute myeloid leukemia fusion partner ETO. Mol Cell Biol 18: 7185-7191, 1998.

9. Yoshida M, Kijima M, Akita M and Beppu T: Potent and specific inhibition of mammalian histone deacetylase both in vivo and in vitro by trichostatin A. J Biol Chem 265: 17174-17179, 1990.

10. Yoshida M, Hoshikawa Y, Koseki K, Mori K and Beppu T: Structural specificity for biological activity of trichostatin A, a specific inhibitor of mammalian cell cycle with potent differentiation-inducing activity in Friend leukemia cells. J Antibiot 43: 1101-1106, 1990

11. Yoshida M, Horinouchi S and Beppu T: Trichostatin A and trapoxin: novel chemical probes for the role of histone acetylation in chromatin structure and function. Bioessays 17: 423-430, 1995.

12. Marks PA, Richon VM and Rifkind RA: Histone deacetylase inhibitors: inducers of differentiation or apoptosis of transformed cells. J Natl Cancer Inst 92: 1210-1216, 2000.

13. Zhou Q, Melkoumian ZK, Lucktong A, Moniwa M, Davie JR and Strobl JS: Rapid induction of histone hyperacetylation and cellular differentiation in human breast tumor cell lines following degradation of histone deacetylase-1. J Biol Chem 275: 35256-35263, 2000.

14. De Ruijter AJ, van Gennip AH, Caron HN, Kemp S and van Kuilenburg AB: Histone deacetylases (HDACs): characterization of the classical HDAC family. Biochem J 370: 737-749, 2003.

15. Warrell RP Jr, He LZ, Richon V, Calleja E and Pandolfi PP: Therapeutic targeting of transcription in acute promyelocytic leukemia by use of an inhibitor of histone deacetylase. J Natl Cancer Inst 90: 1621-1625, 1998.

16. Newmark HL and Young CW: Butyrate and phenylacetate as differentiating agents: practical problems and opportunities. J Cell Biochem Suppl 22: 247-253, 1995.

17. Richon VM, Emiliani S, Verdin E, Webb Y, Breslow R, Rifkind RA and Marks PA: A class of hybrid polar inducers of transformed cell differentiation inhibits histone deacetylases. Proc Natl Acad Sci USA 95: 3003-3007, 1998.

18. Richon VM, Webb Y, Merger R, et al: Second generation hybrid polar compounds are potent inducers of transformed cell differentiation. Proc Natl Acad Sci USA 93: 5705-5708, 1996

19. Jung M, Brosch G, Kölle D, Scherf H, Gerhäuser C and Loidl P: Amide analogues of trichostatin A as inhibitors of histone deacetylase and inducers of terminal cell differentiation. J Med Chem 42: 4669-4679, 1999. 
20. Saito A, Yamashita T, Mariko Y, et al: A synthetic inhibitor of histone deacetylase, MS-27-275, with marked in vivo antitumor activity against human tumors. Proc Natl Acad Sci USA 96: 4592-4597, 1999.

21. Suzuki T, Ando T, Tsuchiya K, et al: Synthesis and histone deacetylase inhibitory activity of new benzamide derivatives. J Med Chem 42: 3001-3003, 1999.

22. Lee BI, Park SH, Kim JW, et al: MS-275, a histone deacetylase inhibitor, selectively induces transforming growth factor beta type II receptor expression in human breast cancer cells. Cancer Res 61: 931-934, 2001.

23. Ryan QC, Headlee D, Acharya M, et al: Phase I and pharmacokinetic study of MS-275, a histone deacetylase inhibitor, in patients with advanced and refractory solid tumors or lymphoma. J Clin Oncol 23: 3912-3922, 2005.

24. Su GH, Sohn TA, Ryu B and Kern SE: A novel histone deacetylase inhibitor identified by high-throughput transcriptional screening of a compound library. Cancer Res 60: 3137-3142, 2000.

25. Takai N, Desmond JC, Kumagai T, et al: Histone deacetylase inhibitors have a profound anti-growth activity in endometrial cancer cells. Clin Cancer Res 10: 1141-1149, 2004.

26. Takai N, Kawamata N, Gui D, Said JW, Miyakawa I and Koeffler HP: Human ovarian carcinoma cells: histone deacetylase inhibitors exhibit antiproliferative activity and potently induce apoptosis. Cancer 101: 2760-2770, 2004.
27. Rimon G, Bazenet CE, Philpott KL and Rubin LL: Increased surface phosphatidylserine is an early marker of neuronal apoptosis. J Neurosci Res 48: 563-570, 1997.

28. Chen Y, Kramer DL, Diegelman P, Vujcic S and Porter CW: Apoptotic signaling in polyamine analogue-treated SK-MEL-28 human melanoma cells. Cancer Res 61: 6437-6444, 2001.

29. Sandberg EM and Sayeski PP: Jak2 tyrosine kinase mediates oxidative stress-induced apoptosis in vascular smooth muscle cells. J Biol Chem 279: 34547-34552, 2004

30. Rahnama F, Shafiei F, Gluckman PD, Mitchell MD and Lobie PE: Epigenetic regulation of human trophoblastic cell migration and invasion. Endocrinology 147: 5275-5283, 2006.

31. Richon VM, Sandhoff TW, Rifkind RA and Marks PA: Histone deacetylase inhibitor selectively induces p21WAF1 expression and gene-associated histone acetylation. Proc Natl Acad Sci USA 97: 10014-10019, 2000.

32. Johnson DG and Walker CL: Cyclins and cell cycle checkpoints. Annu Rev Pharmacol Toxicol 39: 295-312, 1999.

33. Freytag SO: Enforced expression of the c-myc oncogene inhibits cell differentiation by precluding entry into a distinct predifferentiation state in $\mathrm{G}_{0} / \mathrm{G}_{1}$. Mol Cell Biol 8: 1614-1624, 1988.

34. Takeichi M: Cadherin cell adhesion receptors as a morphogenetic regulator. Science 251: 1451-1455, 1991.

35. Graff JR, Herman JG, Lapidus RL, et al: E-cadherin expression is silenced by DNA hypermethylation in human breast and prostate carcinomas. Cancer Res 55: 5195-5199, 1995. 